\title{
A Fresh Look at the Kinetics of Pentosan Removal from Lignocellulosic Biomass
}

\author{
Surendra Pratap Yadav ", Uttam Kumar Ghosh, Amiya Kumar Ray \\ Department of Polymer \& Process Engg., Indian Institute of Technology Roorkee, Roorkee, India \\ Email address: \\ spy.iitr2@gmail.com (S. P. Yadav), ghoshfpt@iit.ac.in (U. K. Ghosh), akrayfpt@iiit.ac.in (A. K. Ray) \\ ${ }^{*}$ Corresponding author
}

To cite this article:

Surendra Pratap Yadav, Uttam Kumar Ghosh, Amiya Kumar Ray. A Fresh Look at the Kinetics of Pentosan Removal from Lignocellulosic Biomass. American Journal of Chemical Engineering. Vol. 4, No. 6, 2016, pp. 161-169. doi: 10.11648/j.ajche.20160406.14

Received: October 4, 2016; Accepted: October 13, 2016; Published: January 7, 2017

\begin{abstract}
The effect of time, temperature and concentration of prehydrolyzing agent on the biomass prehydrolysis have been studied for pentosan removal. Basic kinetic parameters i.e. rate constant, order of reaction, energy of activation and frequency factor were calculated. This study on the kinetics of pentosan removal reveals that the rate of pentosan removal does not follow exactly first order kinetics and shifting of order is observed during the reaction. In searching for a kinetic equation for pentosan removal, it was found that the data was well fitted by an order at higher concentration and by another order at lower concentration of prehydrolyzing agent. The order of reaction of pentosan removal lies between 0.8 to 1.40 . A regression model was developed for $\%$ pentosan removal relating to temperature and time for water prehydrolysis at higher temperatures. This model was well fitted by data given in literature.
\end{abstract}

Keywords: Hemicelluloses, Pentosan, Prehydrolysis, Arrhenius, Reaction Order

\section{Introduction}

The interest for producing chemicals from abundant, renewable and low-cost lignocellulosic materials has been increased in the last decade. Biomass residues available from agricultural and forest processing constitute a potential source for production of different chemicals using enzyme or acid catalyzed hydrolysis [18]. Pentosan is one of the important components belonging to hemicelluloses group. In all kinds of fibers of vegetable origin, this group consists of pentacyclic carbohydrates of varying molecular weights with varying degree of polymerization. The unit carbohydrates belonging to this group are termed as pentoses-the monosachharides consisting of D-xylose, D-arabinose, Larabinose and ribose. Xylose and arabinose are predominant in all natural fibers. The pentosans or pentoses are the major sources of value added products such as Furfural and Hydroxyl methyl furfural which are used in pharmaceutical as well as fuel additives. Furfural is produced by the hydrolysis of xylan rich plant residues. All pentosan containing fibrous materials could be used as raw material for furfural production [18]. Pentosans are also source of bioethanol which can be the major oil substitute in the whole world. The pentosan content in different raw materials is varying from non-wood and wood based fibrous materials. Actually the pentosan content of any fibrous material depends upon the species of that material and the place where it is found. The average pentosan contents of different raw materials are shown in table (1). As shown in table (1), Corn cob has maximum average content of pentosan ranging from $30-40 \%$. Green bamboo, Eucalyptus hybrid has very less pentosan content ranging from $14.50-17.50 \%$ and 14.20 $15.20 \%$ respectively. Non-wood fibrous materials such as rice straw, wheat straw, barley straw, oat straw, rye straw, sugar cane, esparta grasses, sabai grasses, kenaf, jute etc. have higher pentosan content than hardwoods. Coniferous (softwoods) and deciduous (hardwoods) have pentosan content ranging from $7-14 \%$ and $19-26 \%$ respectively [12]. Attempts have been made by various investigators to produce pentoses and furfural in laboratory as well as in pilot scale. For pentosan removal from different lignocellulosic materials different researchers have been used different acids such as $\mathrm{HCl}$ [10], $\mathrm{H}_{2} \mathrm{SO}_{4}[1,22], \mathrm{H}_{3} \mathrm{PO}_{4}$ [29] as catalysts and different metallic catalysts such as $\mathrm{ZnCl}_{2}, \mathrm{SnCl}_{2}, \mathrm{AlCl}_{3}, \mathrm{CaCl}_{2}$ [6] as promoters. Steam treatment (water prehydrolysis at higher 
temperature) without any acid catalyst is also used for pentosan removal $[9,16]$. Concentration of prehydrolyzing agent, process temperature, liquid to solid ratio and reaction time are main process variables in process of pentosan removal [19]. Liquid to solid ratio did not have very much effect on pentosan removal [9]. In this work experimental data had been taken for analysis from previously published work by different authors. In work of X. Luo et al. [16], green bamboo chips had been used for steam pretreatment. Green bamboo chips heated to different temperatures and maintained here for 0-70 min. The pentosan contents of bamboo chips after steam treatment were determined according with the TAPPI standard (T $223 \mathrm{~cm}-01,2001)$. In work of Guha et al. [9], water prehydrolysis of eucalyptus wood chips has been studied. Prehydrolysis conditions were as temperature $-150^{\circ} \mathrm{C}$, liquor material ratio $5: 1$, time to obtain maximum temperature $-90 \mathrm{~min}$, reaction time at maximum temperature-60 min. In work of Bains et al. [2], hydrolysis of rice straw has been taken place by sulphuric acid. Prehydrolysis conditions were as bath ratio -4:1(Liquor to material), reaction temperature- $130^{\circ} \mathrm{C}$, time to obtain maximum temperature $-40 \mathrm{~min}$., reaction time at maximum temperature-2 hrs. In work of Mittal et al. [19], prehydrolysis of bagasse was carried out at different concentrations of sulphuric acid varying from $0.12 \%$ to $1.25 \%$. In this work prehydrolysis conditions were as liquor to material ratio-5:1, time taken to reach maximum temp. $-90 \mathrm{~min}$. and time of reaction at that temperature $-90 \mathrm{~min}$.

Table 1. Pentosan content of different lignocellulosic Materials.

\begin{tabular}{|c|c|c|c|c|}
\hline S.N. & Raw material & Country & $\begin{array}{l}\% \text { Pentosan (based on } \\
\text { oven dry material) }\end{array}$ & Ref. \\
\hline \multirow{3}{*}{1.} & \multirow{3}{*}{ Bagasse } & India & $19.6-20.58$ & {$[5,24]$} \\
\hline & & China & 17.00 & [15] \\
\hline & & Brazil & $25-27$ & [18] \\
\hline \multirow{2}{*}{2.} & \multirow{2}{*}{ Rice straw } & India & $21-25.40$ & {$[2,4,7,25]$} \\
\hline & & Canada & $23-28$ & [12] \\
\hline 3. & Wheat straw & India & 20.60 & [27] \\
\hline 4. & Green Bamboo & China & 17.50 & [16] \\
\hline 5. & Eucalyptus & India & $15.20-15.70$ & {$[11,9]$} \\
\hline \multirow{2}{*}{6.} & \multirow{2}{*}{ Corncob } & India & 37.80 & [2] \\
\hline & & Brazil & $30-40$ & [18] \\
\hline 7. & Rice husk & Brazil & $16-18$ & [18] \\
\hline 8. & Olive stone & Spain & 18.50 & [21] \\
\hline 9. & $\begin{array}{l}\text { ZeaMays stem } \\
\text { pith }\end{array}$ & India & 20.05 & [20] \\
\hline 10. & Red Maple & Florida & 17.0 & [5] \\
\hline 11. & Cotton husks & Brazil & 27.0 & [18] \\
\hline 12. & $\begin{array}{l}\text { Indian mixed } \\
\text { hard woods }\end{array}$ & India & 21.0 & [3] \\
\hline 13. & Banana stem & India & 16.0 & [27] \\
\hline 14. & Barley straw & -- & $24-29$ & [12] \\
\hline 15. & Oat straw & -- & $27-38$ & [12] \\
\hline 16. & Rye straw & -- & $27-30$ & {$[12]$} \\
\hline 17. & $\begin{array}{l}\text { Mentha } \\
\text { waste(oil) }\end{array}$ & India & 18.20 & [2] \\
\hline 18. & Esparta grass & -- & $27-32$ & [12] \\
\hline 19. & Sabai grass & -- & $18-24$ & [12] \\
\hline 20. & Kenaf & -- & $21-23$ & [12] \\
\hline 21. & Jute & -- & $18-21$ & {$[12]$} \\
\hline
\end{tabular}

\section{Kinetics of Hydrolysis of Biomass}

Many researchers $[1,5,16,30]$ have discussed pentosan hydrolysis kinetics. The mechanism for the hemicellulose (especially pentosan) hydrolysis is not accurately modeled because of its complex structure and inability to analyze degradation products completely [16]. Till now, the most studies of pentosan hydrolysis are based on the hypothesis of pseudo-homogenous irreversible first order kinetic equation, although this simplified model do not take into account the formation of monosaccharides and other possible products. In this study a suitable model for pentosan removal is developed from the help of given data by some researchers $[2,9,16]$. The biomass prehydrolysis reaction is a complicated heterogeneous solid-liquid reaction. The whole prehydrolysis reaction involves following steps as described by Bhattacharya et al. [3].

(1) The hydrolyzing agent transports from the bulk liquid to the film surrounding the biomass.

(2) Diffusion of hydrolyzing agent through the film.

(3) Diffusion through the biomass to the reaction sites.

(4) Reaction with pentosans.

(5) Reaction products follow the reverse path out of the biomass.

In general, the rate of a particular reaction can be expressed as a function of the concentration of the reactants as well as the temperature at which the reaction is being carried out. If prehydrolysis of wood or any biomass is considered, the rate of prehydrolyis at any time would be related to the polymer contents of wood or biomass as well as the concentration of the active prehydrolyzing agent and the temperature of the reaction system. It can be written as.....

$$
-r_{P}=f(P, C, T)
$$

Assuming pentosan removal follows $\mathrm{n}^{\text {th }}$ order w.r.t. content of pentosan in biomass and $\mathrm{a}^{\text {th }}$ order w.r.t. concentration of prehydrolyzing agent, equation (1) can be written as......

$$
-r_{P}=k P^{n} C^{a}
$$

$k$ contains the temperature effect along the reaction.

When the liquid-solid ratio is very high and the temperature remains constant, the concentration of prehydrolyzing agent can be assumed as constant. For constant temperature and constant prehydrolyzing agent concentration equation (2) can be written as....

$$
-r_{p}=-\frac{d P}{d t}=k P^{n}
$$

Taking log (base 10) of equation (3) both side,

$$
\log _{10}\left(-\frac{d P}{d t}\right)=n \log _{10} P+\log _{10} k
$$

Comparing equation (4) with equation of straight line, $y=m x+c$ Where; $m=$ slope of straight line, 
$c=$ intercept of straight line.

By plotting equation (4) between $\log _{10}\left(-\frac{d P}{d t}\right)$ and $\log _{10} P$, a straight line will be obtained whose slope will give the order of reaction and intercept will give the value of $\log _{10} k$ for reaction. This method is called differential method of analysis of reaction data described elsewhere [14].

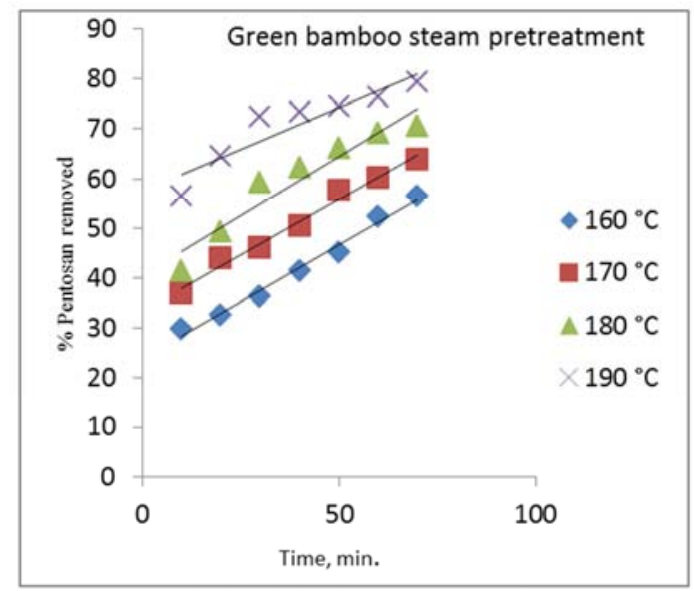

Figure 1a. Effect of time and temperature on removal of Pentosan. Data taken from X. Luo et al. [16].

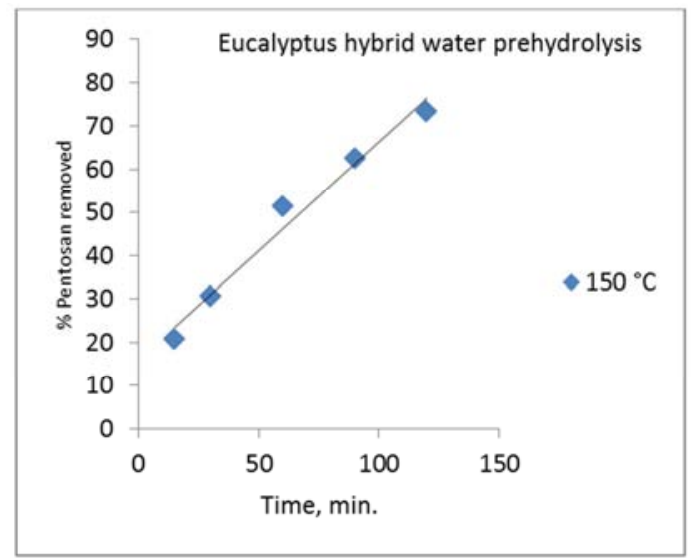

Figure 1b. Effect of time at $150^{\circ} \mathrm{C}$ on removal of pentosan. Data taken from Guha et al. [9].

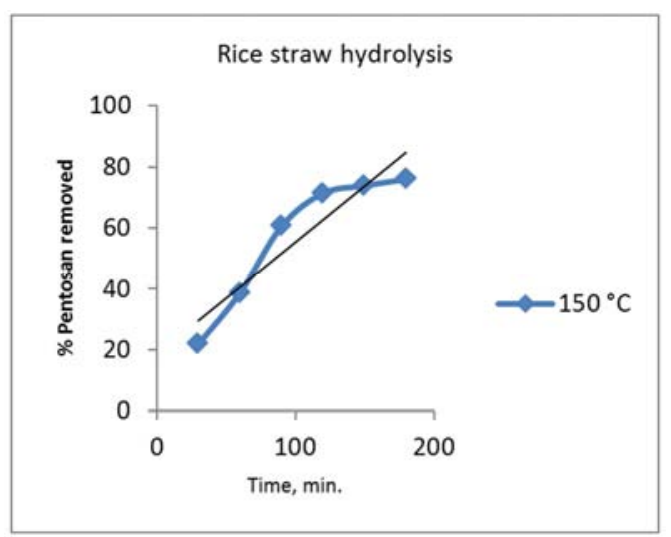

Figure 1c. Effect of time at $150^{\circ} \mathrm{C}$ on pentosan removal. Data Taken from Bains et al. [2].
Table 2. Correlations between \%Pentosan removed with time at different temperatures. Data taken from X. Luo et al. [16].

\begin{tabular}{llc}
\hline Temperature & Correlation & $\mathbf{R}^{2}$ \\
\hline $160^{\circ} \mathrm{C}$ & $\% P R=0.456 t+23.76$ & 0.987 \\
$170^{\circ} \mathrm{C}$ & $\% P R=0.446 t+33.47$ & 0.983 \\
$180^{\circ} \mathrm{C}$ & $\% P R=0.477 t+40.58$ & 0.917 \\
$190^{\circ} \mathrm{C}$ & $\% P R=0.335 t+57.58$ & 0.857 \\
\hline
\end{tabular}

$t=$ time after starting of constant temperature period.

X. Luo et al. [16] studied the pentosan solubility during steam treatment in wide range of reaction conditions. In the heating up period (non isothermal) about 29.5\%, 38\%, 45\% and $58 \%$ pentosan was removed till achieving final constant cooking temperatures $160^{\circ} \mathrm{C}, 170^{\circ} \mathrm{C}, 180^{\circ} \mathrm{C}$ and $190^{\circ} \mathrm{C}$ respectively. It indicates that during heating up-period some fraction of the pentosan degradates. After heating up period, constant temperature period starts. In table (2), correlations with $\mathrm{R}^{2}$ values are given between \% pentosan removed and time in min. for Green Bamboo steam pretreatment. From table (2), it is concluded that as reaction temperature increases, the linear relation between two variables becomes less significant. Actually the pentosan removal mechanism is divided into two stages namely the main pentosan degradation phase and the residual pentosan degradation phase [15]. Main pentosan easily degradates but residual pentosan is difficult to degradate. According to Fig.1a, at lower temperatures $160^{\circ} \mathrm{C}$ to $180^{\circ} \mathrm{C}$, no residual pentosan degradates but at higher temperatures such as $190^{\circ} \mathrm{C}$ residual pentosan degradates. For initial period of reaction when pentosan content is high, the rate of removal of pentosan is high. After initial period, pentosan content in biomass reduces. At this stage rate of removal of pentosan becomes low which indicates residual pentosan degradation phase. Maximum pentosan removed in work of X.Luo and coworkers [16] is about $90 \%$ at $190^{\circ} \mathrm{C}$ for 70 min of reaction period. It shows that it requires more steam pretreatment period for whole pentosan removal at these reactions conditions. According Fig.1b, in heating up period for prehydrolyis of Eucalyptus hybrid about $19.5 \%$ pentosan was removed. After heating up period correlation between \% Pentosan removal and time is given as $\% P R=0.503 t+15.91$ with $\mathrm{R}^{2}=0.975$. In work of Guha et al. [9] degradation of only main pentosan occurs. It is concluded after study of work of Guha et al. [9] and X. Luo et al. [16] that without using any catalyst and steam pretreatment of biomass till temperature of $180^{\circ} \mathrm{C}$, removal of only main part of pentosan takes place. Fig. 1(c) represents work of Bains et al. [2] in which rice straw was hydrlolysed using sulphuric acid. Fig.1c clearly shows that as time increases, the rate of pentosan removal decreases. In their work Bains et al. [2] has shown removal of both parts of pentosan. For initial phase of reaction when main pentosan removes correlation is $\% P R=0.646 t+1.533$ with $\mathrm{R}^{2}=0.994$ and for later phase when the degradation of residual pentosan takes place, the 
correlation is $\% P R=0.076 t+62.26$ with $\mathrm{R}^{2}=0.997$. In work of Bains and coworkers [2], about79\% pentosan removed in $200 \mathrm{~min}$. at reaction temperature $150^{\circ} \mathrm{C}$ using $1.6 \%(\mathrm{w} / \mathrm{w})$ sulphuric acid. In this work about $19 \%$ pentosan removed in heating up period for 40 minutes using $1.6 \%(\mathrm{w} / \mathrm{w})$ sulphuric acid but in work of Guha et al. [11] same amount of pentosan removed in 90 minutes using hot water at $150^{\circ} \mathrm{C}$. It can be concluded that when acid catalysts are used, high pentosan removal can be obtained at low temperatures also.

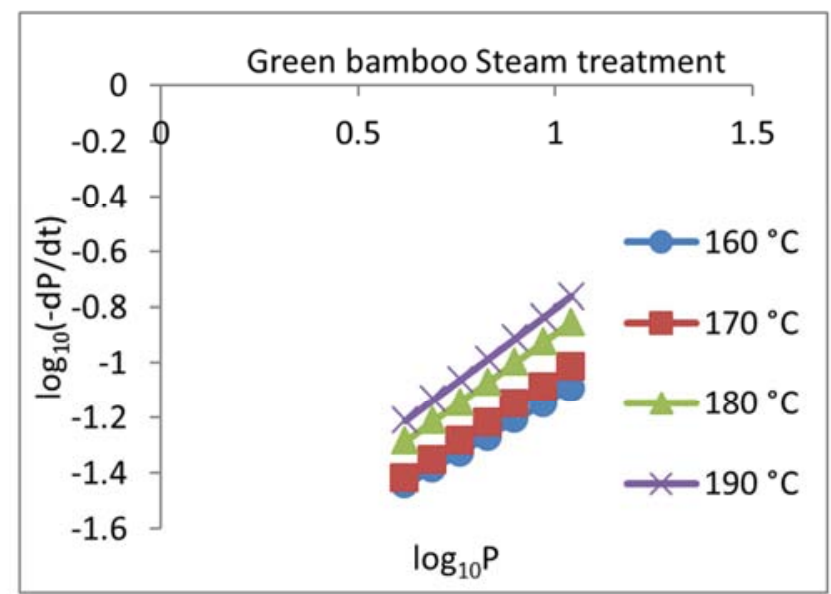

Figure 2a. Variation of logarithm of rate of pentosan removal and logarithm of unreacted remaining pentosan. Data is taken from X. Luo et al. [16].

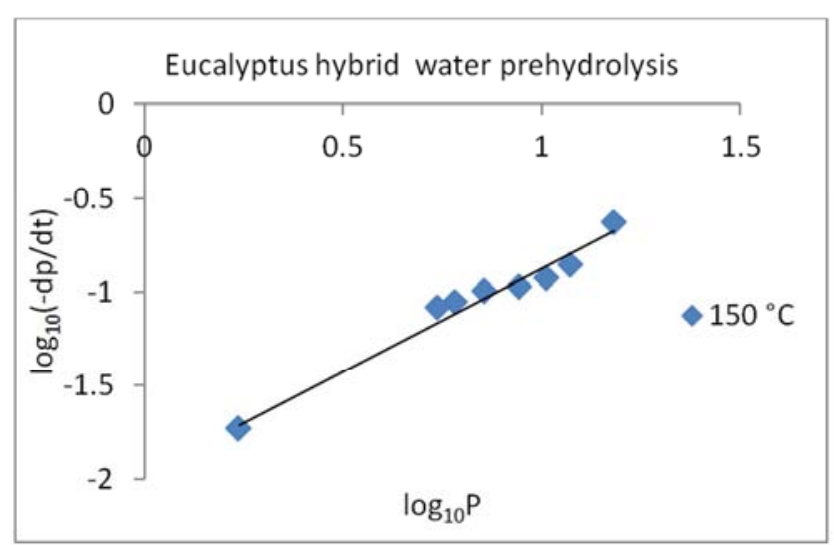

Figure $2 \boldsymbol{b}$. Variation of logarithm of rate of pentosan removal and logarithm of unreacted remaining pentosan. Data is taken from Guha et al. [9].

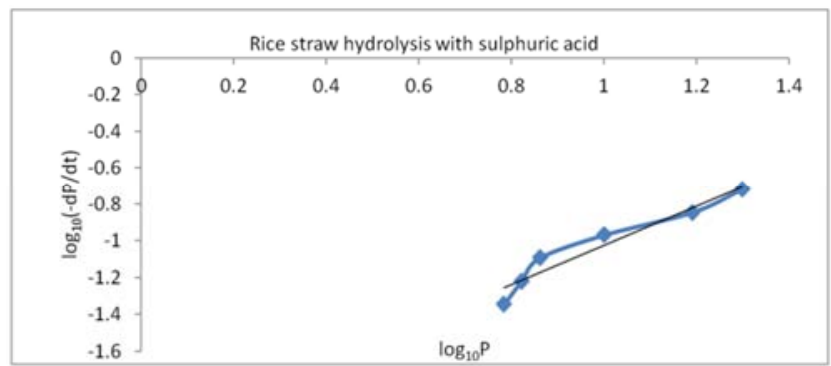

Figure 2c. Variation of logarithm of rate of pentosan removal and logarithm of unreacted remaining pentosan. Data is taken from Mittal et al. [19].

Table 3. Analysis of kinetic data taken from work of X. Luo et al. [16].

\begin{tabular}{lllccc}
\hline Temperature & Part of Pentosan Removed & Kinetic equation in logarithmic form & Order of Reaction & $k$ & $\mathbf{R}^{2}$ \\
\hline $160^{\circ} \mathrm{C}$ & Main & $\log _{10}\left(-\frac{d P}{d t}\right)=1.43 \log _{10} P-2.3636$ & 1.43 & 0.09408 & 0.96 \\
$170^{\circ} \mathrm{C}$ & Main & $\log _{10}\left(-\frac{d P}{d t}\right)=1.27 \log _{10} P-2.2614$ & 1.27 & 0.1042 & 0.98 \\
$180^{\circ} \mathrm{C}$ & Main & $\log _{10}\left(-\frac{d P}{d t}\right)=1.014 \log _{10} P-1.5436$ & 1.014 & 0.2136 & 0.97 \\
& Main & $\log _{10}\left(-\frac{d P}{d t}\right)=0.97 \log _{10} P-1.1413$ & 0.97 & 0.3194 & 0.92 \\
$190^{\circ} \mathrm{C}$ & Residual & $\log _{10}\left(-\frac{d P}{d t}\right)=0.841 \log _{10} P-1.3532$ & 0.841 & 0.2584 & 0.97 \\
\hline
\end{tabular}

In table (3), Kinetic equations for steam pretreatment of Green Bamboo according to work of X. Luo et al. [16] are summarized with $\mathrm{R}^{2}$ values. At higher temperature shifting of order of reaction is observed. The shifting of order during biomass prehydrolyis reaction is also observed by some other researchers $[5,30]$. According to Fig. $2 b$, pentosan removal from Eucalyptus hybrid at $150^{\circ} \mathrm{C}$ hydrolyzed with water has kinetic relation as $\log _{10}\left(-\frac{d P}{d t}\right)=1.1 \log _{10} P-1.980$ with $\mathrm{R}^{2}$ $=0.98$. So order of pentosan removal in this case is 1.1 and reaction rate constant $k$ is $0.0147 \mathrm{~min}-1$. According to Fig.2c, it can be concluded that $\log _{10}\left(-\frac{d P}{d t}\right)$ vs. $\log _{10} P$ graph is not a straight line connecting all data points with precise $\mathrm{R}^{2}$ value. It is observed that the overall curve can be represented by two straight lines for high pentosan content region and low pentosan content region separately. In this case for high pentosan content region, the kinetic equation is $\log _{10}\left(-\frac{d P}{d t}\right)=1.24 \log _{10} P-1.122$ with $\mathrm{R}^{2}=0.97$ and for low pentosan content region the kinetic equation is $\log _{10}\left(-\frac{d P}{d t}\right)=0.81 \log _{10} P-1.793$ with $\mathrm{R}^{2}=0.99$. So order of reaction at high pentosan content region (main pentosan removal) is 1.24 and at low pentosan content region (residual pentosan removal) is $0.81 . k$ value for high pentosan content region is $0.0755 \mathrm{~min}-1$ and for low pentosan content region is $0.0161 \mathrm{~min}^{-1}$. Wilder et al. [31] had taken data from Walter 
et. al. [30] and shown that pentosan removal follows zero order kinetics. In present study the data of Walters [30] was analyzed and found that at higher temperatures pentosan removal follows order of shifting. Following table (4) has shown the kinetic equations obtained from Walters data [30] in present study.

Table 4. Analysis of kinetic data taken from work of Walter's et. al.[30].

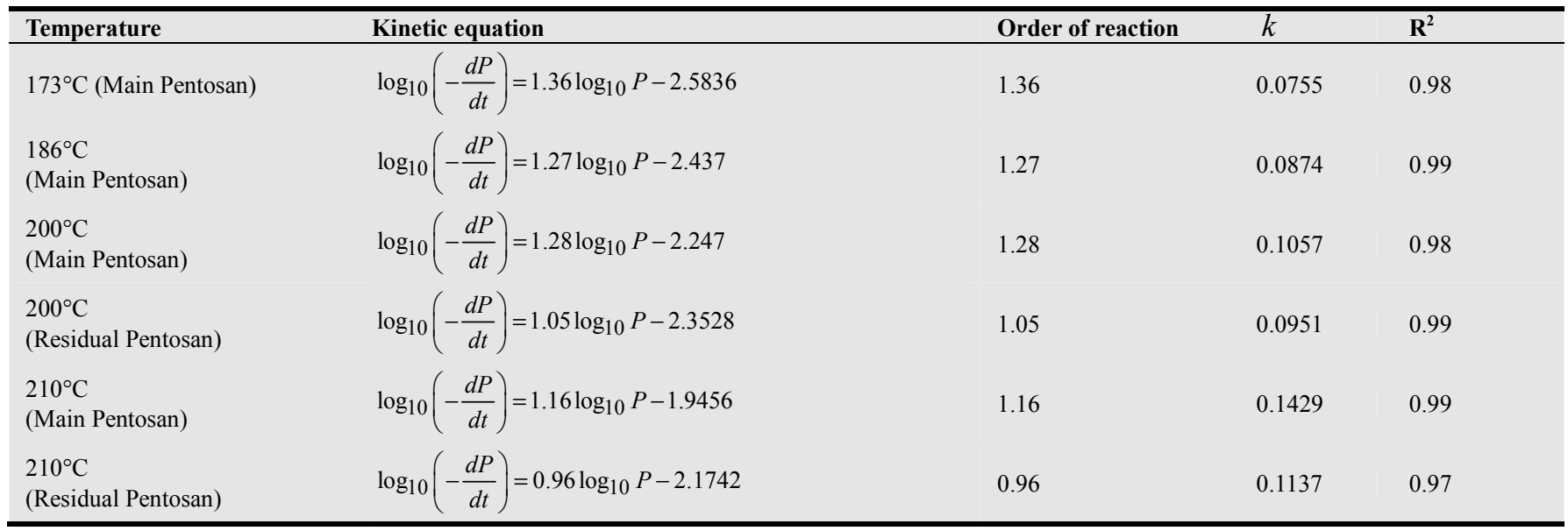

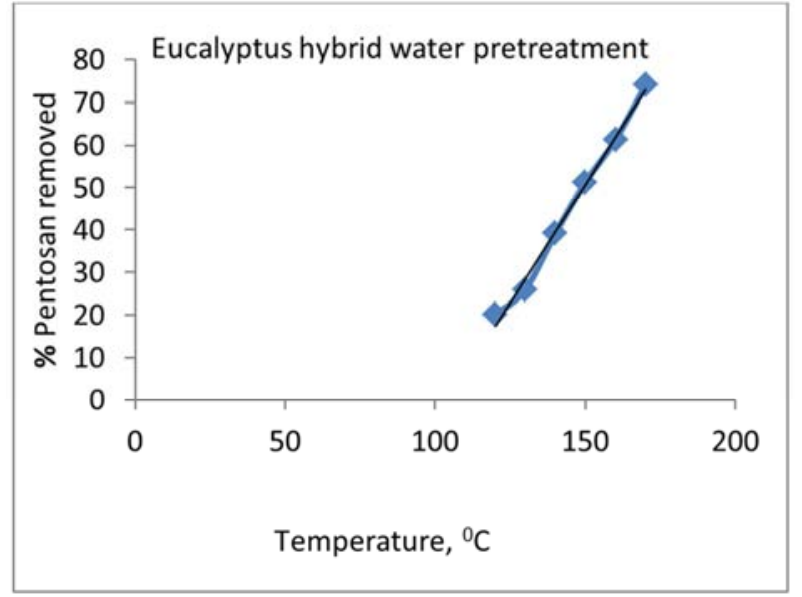

Figure 3a. Effect of temperature on pentosan removal. The data taken from X. Luo et al. [16]. Reaction time on a specific temperature is $70 \mathrm{~min}$. Pentosan removed values are final pentosan removed values after $70 \mathrm{~min}$. of reaction at that specific temperature.

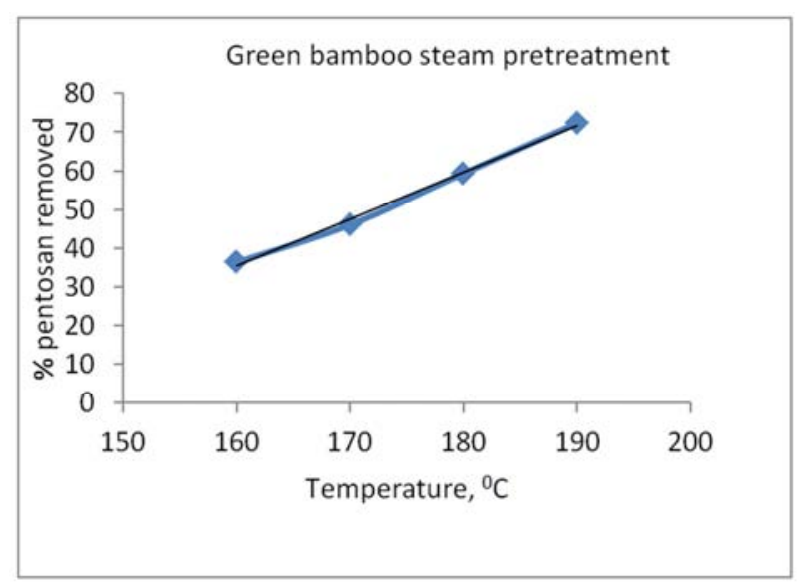

Figure 3b. Effect of temperature on pentosan removal. The data taken from Guha et al. [9]. Reaction time on a specific temperature is $60 \mathrm{~min} . \%$ Pentosan removed values are final pentosan removed values after $60 \mathrm{~min}$. of reaction at that specific temperature.

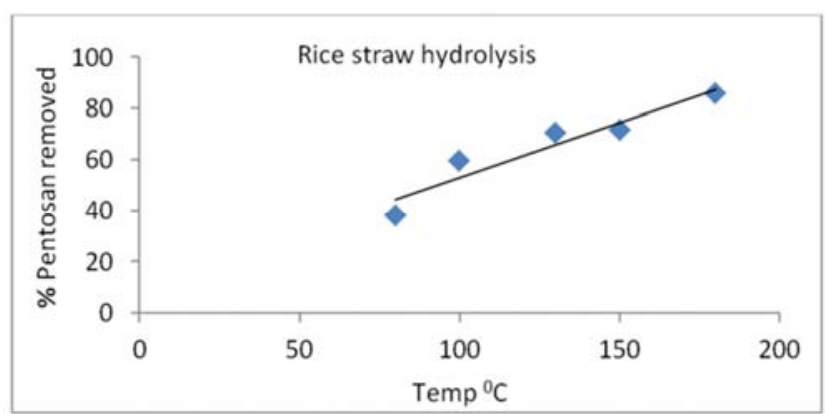

Figure 3c. Effect of temperature on pentosan removal. The data taken from Bains et al. [2].

According to Fig. 3a, \% pentosan removed vs. temperature relationship is given as $\% P R=1.212 T-158.6$ with $\mathrm{R}^{2}=$ 0.995 . This shows approximately a straight line relationship. According to Fig. 3b, the work of Guha et al.[9] shows that at low temperature \% pentosan removal increases by lower rate by increasing temperature, but at higher temperature it increases at higher rate by increasing the temperature. The relationship between \% pentosan removed vs. temperature is given by $\% P R=1.108 T-115.4$ with $\mathrm{R}^{2}=0.993$. According to Fig. 3(c), the work of Bains et al. [2] shows that \% pentosan removal and temperature relation is of irregular type. A correlation for this data is as $\% P R=0.429 T+10.05$ with $\mathrm{R}^{2}=0.90$. In all cases, it is shown that at higher temperature, \% pentosan removal is greater than lower temperature at higher temperature.

Arrhenius equation is given by,

$$
k=A e^{-\frac{E_{a}}{R T}}
$$

Taking natural $\log$ both side of Arrhenius equation.............

$$
\ln k=-\frac{E_{a}}{R T}+\ln A
$$


A Plot of $\ln k$ versus $\frac{1}{T}$ should yield straight line of slope $-\frac{E_{a}}{R}$ and intercept $\ln A$. From Fig. 4a to Fig. 4d, the equations between $\ln k$ vs. $\frac{1}{T}$ with pre-exponential factor and activation energies are summarized here.

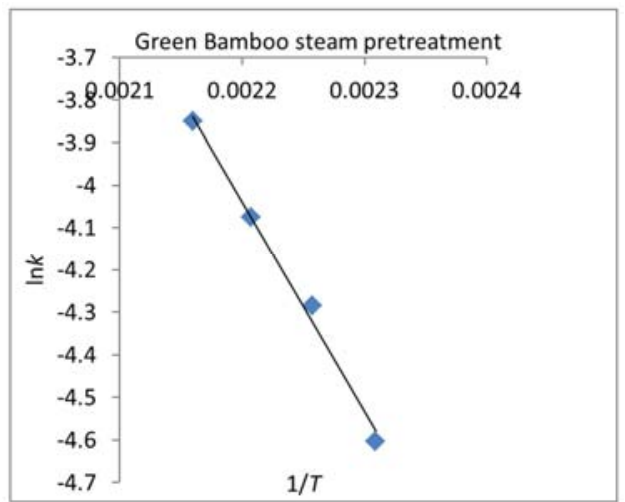

Figure 4a. Relationship between lnk and 1/T. Data taken from X. Luo etal.[16].

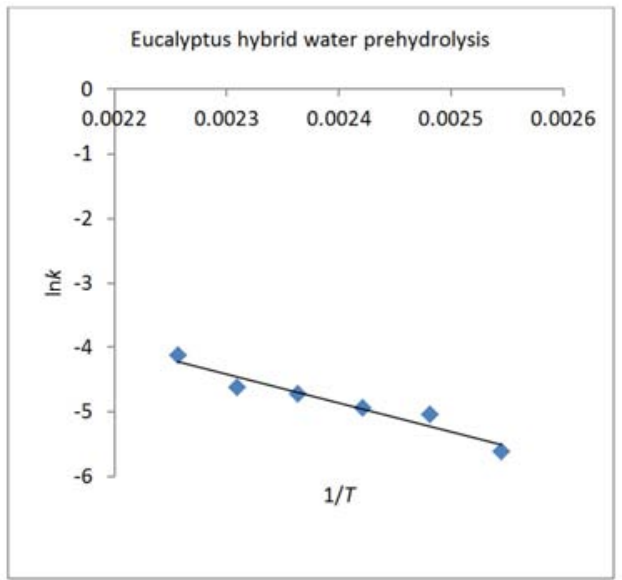

Figure 4b. Relationship between lnk and 1/T. Data taken from Guha et al. [9]. $[3$

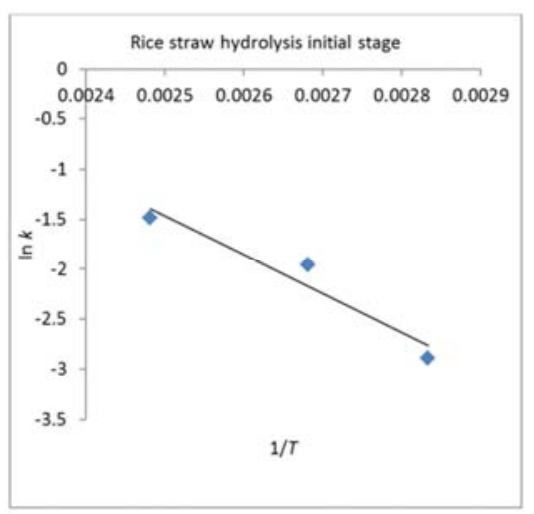

Figure 4c. Relationship between lnk and 1/T. Data taken from Bains et al. [2]

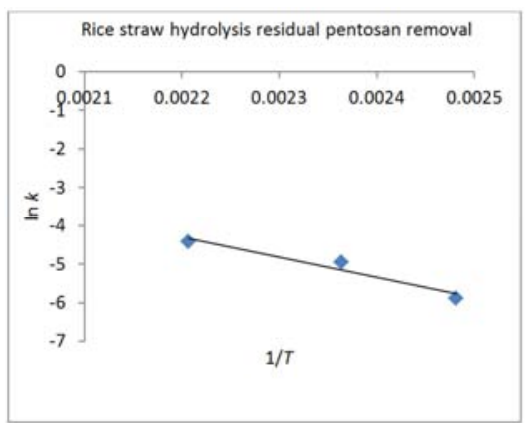

Figure 4d. Relationship between lnk and 1/T. Datataken from Bains et. al. [2].

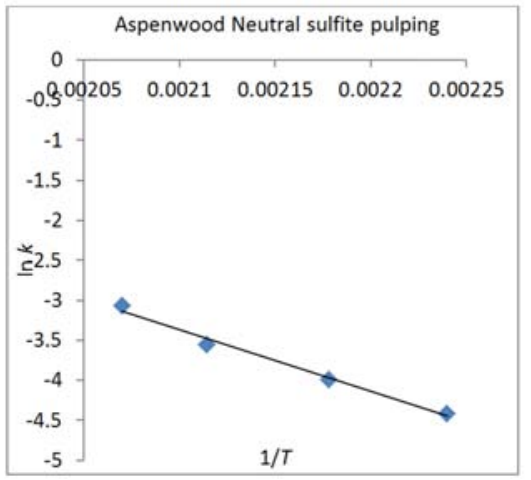

Figure 4e. Relationship between lnk and 1/T. Data taken from Wilder et al. [31].

Table 5. $\ln k$ vs. $\frac{1}{T}$ relations for different raw materials.

\begin{tabular}{|c|c|c|c|c|}
\hline Raw material and process & $\ln k$ vs. $\frac{1}{T}$ relation & $E_{a}(\mathbf{k J} / \mathbf{m o l})$ & $A$ & $\mathbf{R}^{2}$ \\
\hline Green bamboo, steam pretreatment & $\ln k=-4966.0 \frac{1}{T}+6.889$ & 41.287 & 981.45 & 0.993 \\
\hline $\begin{array}{l}\text { Eucalyptus hybrid, hot water } \\
\text { prehydrolysis }\end{array}$ & $\ln k=-4454.0 \frac{1}{T}+5.829$ & 37.031 & 340.018 & 0.934 \\
\hline $\begin{array}{l}\text { Rice straw,sulphuric acid } \\
\text { prehydrolysis( main pentosan removal) }\end{array}$ & $\ln k=-3903.0 \frac{1}{T}+8.291$ & 32.445 & 3987.82 & 0.931 \\
\hline $\begin{array}{l}\text { Rice straw, sulphuric acid prehydrolysis } \\
\text { ( residual pentosan removal) }\end{array}$ & $\ln k=-5242.0 \frac{1}{T}+7.240$ & 43.582 & 1394.1 & 0.941 \\
\hline Aspenwood, Neutral sulfite pulping & $\ln k=-7696.0 \frac{1}{T}+12.79$ & 63.984 & $3.58 \times 10^{6}$ & 0.98 \\
\hline
\end{tabular}


Wilder and coworkers [31] analyzed Walter Pulping Data and found that Pentosan removal kinetics have activation energy $30.800 \mathrm{KJ} / \mathrm{mol}$ and pre exponential factor is $4.26 \times 10^{11}$. In present study Walters data [30] again analyzed with graphical method and activation energy found is 63.984 $\mathrm{kJ} / \mathrm{mol}$ with pre-exponential factor $3.58 \times 10^{6}$. Findley et al.[5] performed experiments on Red maple (Acer rubrum) and found that log-log plot of reaction rate vs. remaining pentosan resulted in a series of straight lines but the slopes of these lines varies with cooking conditions. They have indicated that pentosan removal follows two first order reactions, one is rapid and other is slow but they could not gave any indication that these reactions are parallel or consecutive. The reaction constants of these two reactions vary with temperature. According to Arrhenius equation the range of these two reaction constants are $0.71 \times 10^{-3}$ to $6.38 \times 10^{-3} \mathrm{~min}^{-1}$ and $1.20 \times 10^{-3}$ to $5.81 \times 10^{-3} \mathrm{~min}^{-1}$. Activation energy represented by Findley et al. [5] for these two reactions are 294.315 and $209.512 \mathrm{KJ} / \mathrm{mol}$ which are very high than other reported values by other authors. X. Luo et al. [16] assumed that pentosan removal follows pseudohomogenous first order kinetics and reported pre-exponential factor 4331 and activation energy $48.06 \mathrm{KJ} / \mathrm{mol}$. In present study these values are found different than these reported values.

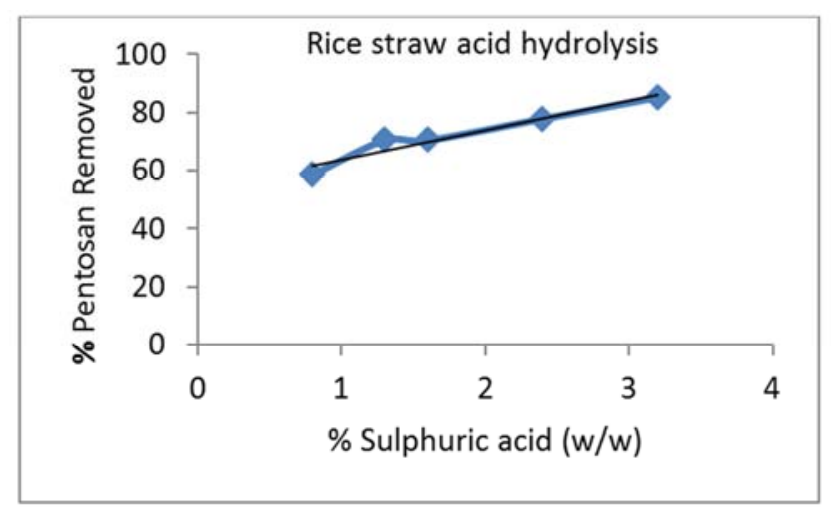

Figure 5a. Effect of acid strength on pentosan removal. The data taken from Bains et al. [2].

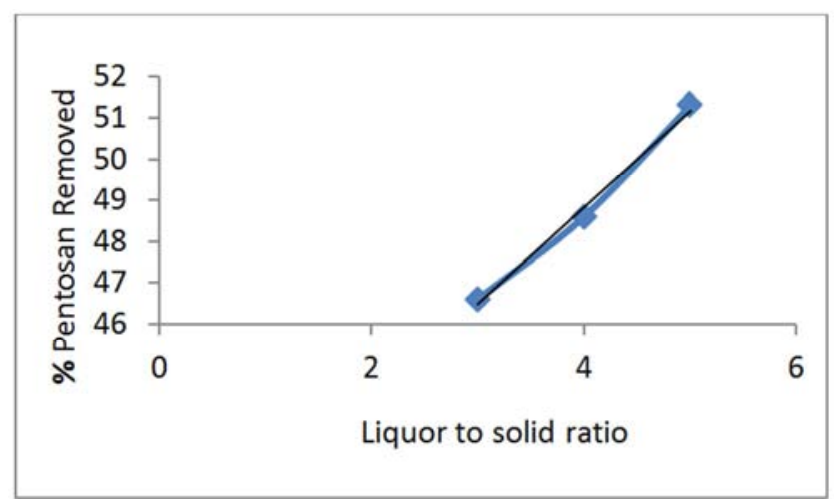

Figure 5b. Effect of liquor to solid ratio on pentosan. The data taken from Guha et al. [9].
According to Fig.5a, \% pentosan removed vs. sulphuric acid plot had been drawn according data taken from Bains and coworkers [2]. The regression relation is written as $\% P R=10.11(\% \mathrm{~S})+53.66$ with $\mathrm{R}^{2}=0.94$. When sulphuric acid percentage is increased then \% pentosan removal is also increased. In the work of Bains et al. [2] at 3.5\% sulphuric acid about $90 \%$ pentosan is removed in 2 hours. In Fig. 5b, \% pentosan removal vs. Liquor to solid ratio is shown from data of Guha et al. [9]. The regression relation is written as $\% P R=2.35(L S R)+39.43$ with $\mathrm{R}^{2}=0.99$. It is shown that when liquid to solid ratio increased from $3: 1$ to $5: 1$, the pentosan removal increased from $46 \%$ to $51 \%$. It is concluded that liquid to solid ratio have less effect than other variables.

\section{Model Development for Pentosan Removal}

A non-linear regression model has been developed using Levenberg-Marquardt (LM) algorithm for finding the \% pentosan removed in biomass steam pretreatment process for different time and temperatures. The objective function that is minimized is the sum of squares of the errors. To develop this model data is taken from Guha et al. [9] and X. Luo et al. [18]. The non-linear model is as follows.....

$$
y=a_{0}+a_{1} t+a_{2} T+a_{12} t T
$$

Where $y=\%$ Pentosan removed (Based on total pentosan initially in oven dry material)

$t=$ time, min., $T=$ temperature in ${ }^{0} \mathrm{C}$.

The values of Different parameters and statistical parameters of this model are as tabulated in Table (6) \& (7) respectively.

Table 6. Model Parameters.

\begin{tabular}{lll}
\hline Parameter & Value & 95\% confidence \\
\hline$a_{0}$ & -48.96257 & 25.49 \\
$a_{1}$ & 0.0028025 & 0.002308 \\
$a_{2}$ & 0.5473429 & 0.208568 \\
$a_{12}$ & 0.0015339 & 0.318765 \\
\hline
\end{tabular}

Table 7. Statistical Parameters.

\begin{tabular}{ll}
\hline Statistical Parameters & Values \\
\hline $\mathrm{R}^{2}$ & 0.97 \\
$\mathrm{R}^{2} \mathrm{adj}$ & 0.96 \\
$\mathrm{Rmsd}$ & 1.0208 \\
Variance & 14.06 \\
\hline
\end{tabular}




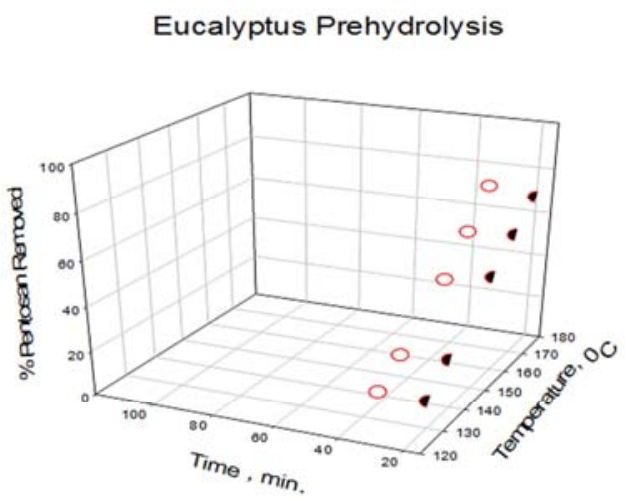

- \% Pentosan removed experimental $\%$ Pentosan Removed Predicted by Given Model

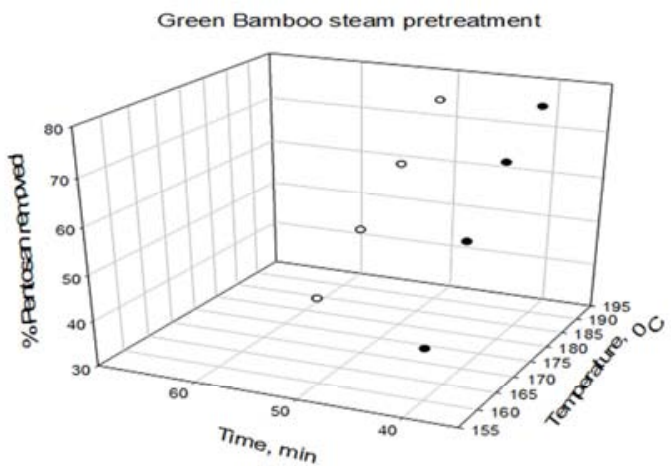

\% Pentoan removed experimental $\%$ Pentosan removed Predicted by model

Figure 6a. 3-D scatter plots showing \% pentosan removed with different time and temperatures for Eucalyptus and Green bamboo steam pretreatment. The values obtained by experiments as well as from given model are in very good agreement with each other.

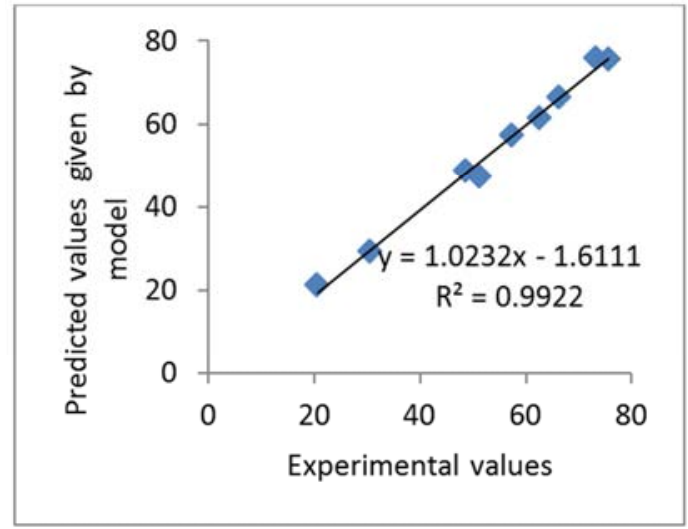

Figure 6b. Comparison between experimental and predicted values. The graph between predicted as well as experimental values shows that model predicts the experimental values very well.

\section{Conclusion}

It has been observed that there is a wide variation in the average pentosan content of the different materials worldwide. In steam prehydrolysis till $170^{\circ} \mathrm{C}$ only main part of pentosan removes. At higher temperatures residual part of pentosan also degradates. Residual pentosan can also be removed at lower temperatures using acid catalysts. During prehydrolysis of biomass, the order of pentosan removal alters as reaction proceeds. For initial stage of reaction, \%pentosan content in biomass is high. For this stage rate of pentosan removal and order of reaction is high. At low pentosan content, rate of removal and order of reaction is low. The order of pentosan removal given by different researchers and found out in this study vary with each other. Average order for main pentosan removal found in this study is approximately 0.84-1.43. For residual pentosan removal approximate order is 0.80-0.97. Activation energy for main pentosan removal lies between $30-40 \mathrm{~kJ} / \mathrm{mol}$. For residual pentosan removal it is about 43 $\mathrm{KJ} / \mathrm{mol}$. Pre-exponential factor have also large range of variation given by different researchers and found in present study. Pre-exponential factor lies in the range of 340 to $3.58 \times 10^{6}$. For pentosan removal temperature, time and acid concentration are the main important process variables to affect the process. Solid-liquid ratio has very little effect on pentosan removal.

\section{Nomenclature}

$-r_{P}=$ rate of pentosan removal, grams pentosan removed/(100 g. O.D. wood $)(\min$.

$n=$ order of reaction

$P=$ unreacted pentosans, gram pentosans $/(100 \mathrm{~g}$. O.D.charged material)

$C=$ concentration of active prehydrolyzing agent

$k=$ reaction rate constant, units consistent with order of reaction

$\% P R=$ percentage pentosan removed (based on total initial pentosan in material)

$T=$ temperature, ${ }^{\circ} \mathrm{C}$

$t=$ time, $\min$.

$E_{a}=$ activation energy, $\mathrm{kJ} / \mathrm{mol}$

$A=$ pre-exponential factor

$R=$ universal gas constant

$\% S=$ percentage sulphuric acid $(\mathrm{w} / \mathrm{w})$

\section{References}

[1] Aguilar R., Ramirez J. A., Garrote G., Vazquez M. Kinetic study of the acid hydrolysis of sugar cane bagasse. J. Food Eng. 2002; 55:309-318.

[2] Bains B. S., Puri S. C., Chawla J. S. Thermal hydrolytic studies on lignocellulosic Wastes. J. IPPTA 1977(July, Aug. \& Sept.); 15:201-204.

[3] Bhattacharya Prashant K., De Sirshendu, Haldar Raghunath, Thakur Rajeev. Kinetic studies on soda -anthraquinone pulpingof Indian mixed hardwoods. J. TAPPI 1992(Aug.); 123-127.

[4] Bhardwaj N. K., GoyalSanjeev K., Gupta Ajay, Upadhyaya J. S., Ray A. K. Soda \& Soda-anthraquinone pulping of rice straw. J. IPPTA 1999; 58(3):180-185. 
[5] Findley Marshall E., Nolan W. J. A kinetic Study of the Reactions. J.TAPPI 1956; 39(11):758-768.

[6] Goldstein, I. S., Helena, P., Pittman, J. L., Strouse, B. A. and Searingelli, P., Proc. $5^{\text {th }}$ symposium on Biotechnology for fuels and Chemicals, Gatlingburg, Tennessee, USA, 1983.

[7] Goyal S. K., Ray A. K., Bhardwaj N. K., Gupta A. Pulping studies of rice straw using Soda and soda anthraquinone process. Proc. TAPPI 1998; Pulping Conference: 227-238.

[8] Goyal S. K., Ray A. K. Optimization of bleaching parameters for bagasse pulp: An economic analysis. Proc. TAPPI 1989; Pulping Conference: 703-707.

[9] Guha S. R. D., Singh S. V., Gopichand S. Kinetic and Mechanism of Water Prehydrolysis of Eucalyptus Hybrid. J. IPPTA Souvenir; 1977:22-27.

[10] Herrera A, Tellez-Luis SJ, Ramirez JA, Vazquez M., Production of xylose from sorghum straw using hydrochloric acid. J. Cereal Sci 2003; 37(3):267-274.

[11] Htut Ye, Biyani S. S., Kumar Prem, Bapuji G., Mittal K. C., Naithani N. K. High Alpha Pulp From Bagasse. J. IPPTA Souvenir 1977; 57-63.

[12] Hurter A. M. Utilization Of Annual Plants And Agricultural Residues For the Production of Pulp And paper. TAPPI Proceedings, 1988 Pulping Conference: 139-161.

[13] Kobayashi T, Sakai Y. Hydrolyis rate of pentosan of hardwood in dilute sulphuric acid. J. Bull. Agric. Chem. Soc.Jpn., 1956, 20(1):1.

[14] Levenspiel O., 1999. Chemical Reaction Engineering, third ed., John Wiley \& Sons, pp. 63-67.

[15] Liu Yuxin, Liu Yanxue, Wang Zhongliang, PengJinhui. Alkaline Hydrolysis Kinetics Modeling of Bagasse Pentosan Dissolution. Bioresources 2014; 9(1):445-454.

[16] LuoXiaolin, Ma Xiaojuan, Hu Huichao, LiCanghai, Cao Shilin, Huang Liulian, Chen Lihui. Kinetic study of pentosan solubility during heating and reacting processes of steam treatment of green bamboo. J.Bioresource Technology 2013;130:769-776.

[17] LuoXiaolin, Hu Huichao, Ma Xiaojuan, Cao Shilin, Li Canghai, Huang Liulian, Chen Lihui. A novel model for process of pentosan digestion during steam treatment of green bamboo. J. CIESC 2013;64(5):1766-1772.

[18] Mansilla Hector D., Baeza Jaime, Urzua Sergio, Maturana Gabriel, VillasenorJorge, Duran Nelson. Acid -Catalysed hydrolysis of rice hull: Evaluation of Furfural production. $\mathrm{J}$ Bioresource Technology 1988; 66: 189-193.

[19] Mittal K. C. Optimisation Of Prehydrolysis-Kraft Delignification Of Bagasse. Proc. TAPPI 1988;Pulping Conference 47-51.

[20] Mittal J. P., Biswas B. Studies in the preparation of furfural from Zea mays stem pith. J. IPPTA 1977(July, Aug. \& Sept.); 15(3):209-216.

[21] Montane Daniel, Salvado Joan, Torras Carles, Farriol Xavier. High -temperature dilute-acid hydrolysis of olive stones for furfural production. J. Biomass and Bioenergy 2002;22:295304.

[22] Nguyen QA, Tucker MP, Keller FA, Eddy FP. Two-stage dilute-acid pretreatment of softwoods. J. Appl Biochem Biotech 2000; 84-86:561-576.

[23] Rodriguez-Chong A, Ramirez JA, Garrote G, Vazquez M. Hydrolysis of sugar cane bagasse using nitric acid: a kinetic assessment. J. Food Eng.2004; 61(2):143-152.

[24] Ray A. K., Kumar Vivek, Dharm Dutt, Mittal K. C.. Comparision of ECF bleaching Sequences of Bagasse Pulp, IPPTA Issue2005, 77-82.

[25] Ray A. K., MathurAshish, Verma K. V. An attempt to analyze rice straw based mechano-chemical pulp forprocessing. 1991 Pulping Conference pg. no. 223-233.

[26] Ray A. K., Carrasco F., Kakta B. V. Steam explosion high yield pulp from mill wet bagasse. ININ FPCC, April 6-9, 1992 PRCC (China).

[27] Sood Y. V., Kapoor S. K. Modified soda pulping of wheat straw. J. IPPTA 1984(march); 21(1):81-86.

[28] Sharma D. K., Das K. Mechanism of two stage acid hydrolysis of bagasse by $\mathrm{HCl}$ under atmospheric pressure conditions. J. Indian chemical engineer 1987; 29: 68-71.

[29] Vazquez M, Oliva M, Tellez-Luis SJ, Ramirez JA. Hydrolysis of sorghum straw using phosphoric acid: evaluation of furfural production. J. Bioresource technology 2007; 98: 3053-3060.

[30] Walters, W. Z., "The Effect of Elevated Temperatures on the Neutral Sulfite Pulping Process," Doctor's Dissertation, Appleton, Wis., The institute of Paper Chemistry, 1959; Walters, W. Z. and May, M. N., Tappi 43:11,881(1960).

[31] Wilder Harry D., Han S. T. A comparison of the kinetics of the neutral sulfite and kraft pulping Process. J. TAPPI 1962(January);45(1):1-9. 